\title{
Confusion profusion: the arguments about the site
}

"If JET goes to Ispra, it is better that it does not get done at all." Senior official, Culham fusion research centre.

"If JET does not go to Ispra, it is not worth doing." Senior official, European Commission.

Culham and Ispra are probably the two main contending sites for the JET project. France's involvement in the Superphénix fast breeder is thought to make its bid for Cadarache more an attempt to score political points than a determined effort to win the project. Garching's candidacy is regarded with more severe respect and remains a powerful contender, but it has not planned to take JET in the way that Culham, with the design team, has done.

Only Italy defends Ispra with vigour; apart from Britain, though, none of the Nine openly backs Culham. The arguments concerning all the sites are finely balanced. The technical assessment of the Commission's site committee looked at the alternatives in terms of power supplies, infrastructure, safety and social facilities. On each criterion each site was fair to excellent: no site was best on all aspects, but all sites were suitable for the construction of JET.

It was chiefly on the power supply and social aspects that the Commission originally chose Ispra. It is fed directly from a conveniently located power supply; it already has an adequate infrastructure and social facilities, including an international school; it has staff already available for the project; and it has the equipment and expertise needed for the heavy engineering involved in handling large-scale plant and materials.

But the arguments in favour of Ispra now, if they didn't do so before, traverse broader territory than this. Perhaps the most potent actually comes from its supporters in the Commission itself, representing the collective Community interest. It is in the best long term Community interests, the argument goes, that the project be pursued as a Community effort. The project, particularly as it is largely Community financed, should therefore preferably be sited at a Community centre. And the premier establishment of the Community's Joint Research Centre (JRC) - indeed the only one capable of handling the project-is at Ispra, in northern Italy.

The argument goes further, into psychology. Ispra, it says, has been dogged by uncertainty in recent years, and the latest programme of research is due to end this year. Although much of the multi-annual programme planned for 1977-80 will be conducted at Ispra, JET would insure its own future as the Community's leading research centre, which might in turn halt the fragmentation of research. Siting the project at Ispra would at the same time compensate Italy's loss by its exclusion from the UK-West Germany-Netherlands Gas Centrifuge Treaty for Uranium Enrichment.

The case against Ispra has come mainly from Britain, a point that has not gone unnoticed amongst senior Community officials. It turns most importantly on the project's chances of success. The chief scientist at the Energy Department, Dr Walter Marshall, not known as a fusion enthusiast, puts it this way: there is "an appreciable chance" that the project will fail, not because it is badly conceived but because it is so ambitious; it should not therefore go to any site which "lacks experience and knowhow in solving the plasma physics problems that are bound to arise." Ispra's fusion experience (often described in Britain as "modest") is not great.

Marshall does think that the proiect should go ahead. But he judges that other sites, including Culham, satisfy his criterion in a way that Ispra does not. Moreover, he is "very much frightened" that if the counterarguments about symbols of European collaboration win the day, then the proiect really will be a failure. If he could be persuaded of the scientific capability of a site, he has said, he would recommend it, but this he says has not been done; there had only been a "review of the characteristics" of the sites.

The implication is that a site (like Ispra) ought not to be chosen for an additional reason-to solve an administrative problem. Others allege in addition that Ispra's resources, and its capacity to get them, are not great. It has even been said that scientists would be reluctant to work at Ispra, especially as it has not managed a large project before. Past labour problems add to its reported reputation for mismanagement-a reputation also pinned on the Commission, whose allegedly closed mind over the matter has proved a sore point in Britain. That Ispra could prove to be the most expensive site. which is also suggested, is a point that Guido Brunner, European Research Commissioner, disputes. $\mathrm{He}$ says the differences in cost between the various sites is no more than $10 \%$.

The arguments in favour of Culham are partly the arguments against Ispra reversed. Culham, it is said, is already a centre of excellence in fusion, commanding large experience and resources, possessing a good "track record" and making progress that is more than comparable with the USA and USSR. Furthermore, it not only fits the bill on such essential criteria as power supplies, it also has the land ready to take JET and, most importantly, a team already settled there to continue the work it has successfully begun. Such continuity, it is argued, ensures the maximum chances of success. Culham, says Alex Eadie, junior minister at the Energy Department, is the best site on technical, scientific and operational grounds. But another reason offered in support of Culham is more nakedly political: namely, that there is as yet no high technology Community project in Britain. This gives it some sort of advantage over Garching, for example, since West Germany has the Patent Office and the European Molecular Biology Organisation.

Arguments against Culham throw doubts on its back-up facilities, on the lack of a school and so on. Beyond these, though, it is said that expertise in fusion is not really relevant for much of the project's duration, since most of the time would be spent in JET's construction; moreover, any problems that arose would probably be too big for any one laboratory to solve alone. More subtle arguments point to the recent experience with the Dragon high temperature reactor project at Winfrith, Dorset, during which Britain attracted from many European countries criticism of its foot-dragging, if not obstructionist, tactics over the project's fate.

The site stand-off preventing JET's take-off is thus a complicated affair. It has tried the patience of the contending host countries, whose Community spirit is already under scrutiny. It has aggravated the frustrations of the smaller member states who these days have enough reason to feel left out in the cold. And it has threatened the role of the Commission, whose ambiguous position has rendered its influence and authority more tenuous than it might otherwise have been. The Community's worst enemies couldn't ask for more. 